\title{
CARTA DEMOCRÁTICA INTERAMERICANA
}




$$
\text { . }
$$




\section{CARTA DEMOCRÁTICA INTERAMERICANA}

VIGÉSIMO OCTAVO PERÍODO EXTRAORDINARIO DE SESIONES

11 de septiembre de 2001 Lima, Perú

CARTA DEMOCRÁTICA INTERAMERICANA

\section{LA ASAMBLEA GENERAL,}

CONSIDERANDO que la Carta de la Organización de los Estados Americanos reconoce que la democracia representativa es indispensable para la estabilidad, la paz y el desarrollo de la región y que uno de los propósitos de la OEA es promover y consolidar la democracia representativa dentro del respeto del principio de no intervención;

RECONOCIENDO los aportes de la OEA y de otros mecanismos regionales y subregionales en la promoción y consolidación de la democracia en las Américas;

RECORDANDO que los Jefes de Estado y de Gobierno de las Américas reunidos en la Tercera Cumbre de las Américas, celebrada del 20 al 22 de abril de 2001 en la ciudad de Quebec, adoptaron una cláusula democrática que establece que cualquier alteración o ruptura inconstitucional del orden democrático en un Estado del Hèmisferio constituye un obstáculo insuperable para la participación del gobierno de dicho Estado en el proceso de Cumbres de las Américas;

TENIENDO EN CUENTA que las cláusulas democráticas existentes en los mecanismos regionales y subregionales expresan los mismos objetivos que la cláusula democrática adoptada por los Jefes de Estado y de Gobierno en la ciudad de Quebec; 
REAFIRMANDO que el carácter participativo de la democracia en nuestros países en los diferentes ámbitos de la actividad pública contribuye a la consolidación de los valores democráticos y a la libertad y la solidaridad en el Hemisferio;

CONSIDERANDO que la solidaridad y la cooperación de los Estados americanos requieren la organización política de los mismos sobre la base del ejercicio efectivo de la democracia representativa y que el crecimiento económico y el desarrollo social basados en la justicia y la equidad y la democracia son interdependientes y se refuerzan mutuamente;

REAFIRMANDO que la lucha contra la pobreza, especialmente la eliminación de la pobreza crítica, es esencial para la promoción y consolidación de la democracia y constituye una responsabilidad común y compartida de los Estados americanos;

TENIENDO PRESENTE que la Declaración Americana de los Derechos y Deberes del Hombre y la Convención Americana sobre Derechos Humanos contienen los valores y principios de libertad, igualdad y justicia social que son intrínsecos a la democracia;

REAFIRMANDO que la promoción y protección de los derechos humanos es condición fundamental para la existencia de una sociedad democrática, y reconociendo la importancia que tiene el continuo desarrollo y fortalecimiento del sistema interamericano de derechos humanos para la consolidación de la democracia;

CONSIDERANDO que la educación es un medio eficaz para fomentar la conciencia de los ciudadanos con respecto a sus propios países $y$, de esa forma, lograr una participación significativa en el proceso de toma de decisiones, y reafirmando la importancia del desarrollo de los recursos humanos para lograr un sistema democrático y sólido;

RECONOCIENDO que un medio ambiente sano es indispensable para el desarrollo integral del ser humano, lo que contribuye a la democracia y la estabilidad política;

TENIENDO PRESENTE que el Protocolo de San Salvador en materia de derechos económicos, sociales y culturales resalta la importancia de que tales derechos sean reafirmados, desarrollados, perfeccionados y protegidos en función de consolidar el régimen democrático representativo de gobierno; 
RECONOCIENDO que el derecho de los trabajadores de asociarse libremente para la defensa y promoción de sus intereses es fundamental para la plena realización de los ideales democráticos;

TENIENDO EN CUENTA que, en el Compromiso de Santiago con la Democracia y la Renovación del Sistema Interamericano, los Ministros de Relaciones Exteriores expresaron su determinación de adoptar un conjunto de procedimientos eficaces, oportunos y expeditos para asegurar la promoción y defensa de la democracia representativa dentro del respeto del principio de no intervención; y que la resolución AG/RES. 1080 (XXI-O/91) estableció, consecuentemente, un mecanismo de acción colectiva en caso de que se produjera una interrupción abrupta o irregular del proceso político institucional democrático o del legítimo ejercicio del poder por un gobierno democráticamente electo en cualquiera de los Estados Miembros de la Organización, materializando asi una antigua aspiración del Continente de responder rápida y colectivamente en defensa de la democracia;

RECORDANDO que, en la Declaración de Nassau (AG/DEC. 1 (XXII-O/92)), se acordó desarrollar mecanismos para proporcionar la asistencia que los Estados Miembros soliciten para promover, preservar y fortalecer la democracia representativa, a fin de complementar y ejecutar lo previsto en la resolución AG/RES. 1080 (XXI-O/91);

TENIENDO PRESENTE que, en la Declaración de Managua para la Promoción de la Democracia y el Desarrollo (AG/DEC. 4 (XXIII-O/93)), los Estados Miembros expresaron su convencimiento de que la democracia, la paz y el desarrollo son partes inseparables e indivisibles de una visión renovada e integral de la solidaridad americana, y que de la puesta en marcha de una estrategia inspirada en la interdependencia y complementariedad de esos valores dependerá la capacidad de la Organización de contribuir a preservar y fortalecer las. estructuras democráticas en el Hemisferio;

CONSIDERANDO que, en la Declaración de Managua para la Promoción de la Democracia y el Desarrollo, los Estados Miembros expresaron su convicción de que la misión de la Organización no se limita a la defensa de la democracia en los casos de quebrantamiento de sus valores $y$ principios fundamentales, sino que requiere además una labor permanente y creativa dirigida a consolidarla, así como un esfuerzo permanente para prevenir y anticipar las causas mismas de los problemas que afectan el sistema democrático de gobierno; 
TENIENDO PRESENTE que los Ministros de Relaciones Exteriores de las Américas, en ocasión del trigésimo primer período ordinario de sesiones de la Asamblea General, en San José de Costa Rica, dando cumplimiento a la expresa instrucción de los Jefes de Estado y de Gobierno reunidos en la Tercera Cumbre, celebrada en la ciudad de Quebec, aceptaron el documento de base de la Carta Democrática Interamericana y encomendaron al Consejo Permanente su fortalecimiento y ampliación, de conformidad con la Carta de la OEA, para su aprobación definitiva en un periodo extraordinario de sesiones de la Asamblea General en la ciudad de Lima, Perú;

RECONOCIENDO que todos los derechos y obligaciones de los Estados Miembros conforme a la Carta de la OEA representan el fundamento de los principios democráticos del Hemisferio; y

TENIENDO EN CUENTA el desarrollo progresivo del derecho internacional y la conveniencia de precisar las disposiciones contenidas en la Carta de la Organización de los Estados Americanos e instrumentos básicos concordantes relativos a la preservación y defensa de las instituciones democráticas, conforme a la práctica establecida,

RESUELVE:

Aprobar la siguiente

\author{
CARTA DEMOCRÁTICA INTERAMERICANA \\ 1 \\ LA DEMOCRACIA Y EL SISTEMA INTERAMERICANO
}

Articulo 1

Los pueblos de América tienen derecho a la democracia y sus gobiernos la obligación de promoverla y defenderla.

La democracia es esencial para el desarrollo social, político y económico de los pueblos de las Américas.

Artículo 2

El ejercicio efectivo de la democracia representativa es la base del estado de derecho y los regímenes constitucionales de los Estados 
Miembros de la Organización de los Estados Americanos. La democracia representativa se refuerza y profundiza con la participación permanente, ética y responsable de la ciudadania en un marco de legalidad conforme al respectivo orden constitucional.

\section{Artículo 3}

Son elementos esenciales de la democracia representativa, entre otros, el respeto a los derechos humanos y las libertades fundamentales; el acceso al poder y su ejercicio con sujeción al estado de derecho; la celebración de elecciones periódicas, libres, justas y basadas en el sufragio universal y secreto como expresión de la soberanía del pueblo; el régimen plural de partidos y organizaciones políticas; y la separación e independencia de los poderes públicos.

\section{Artículo 4}

Son componentes fundamentales del ejercicio de la democracia la transparencia de las actividades gubernamentales, la probidad, la responsabilidad de los gobiernos en la gestión pública, el respeto por los derechos sociales y la libertad de expresión y de prensa.

La subordinación constitucional de todas las instituciones del Estado a la autoridad civil legalmente constituida y el respeto al estado de derecho de todas las entidades y sectores de la sociedad son igualmente fundamentales para la democracia.

\section{Artículo 5}

El fortalecimiento de los partidos y de otras organizaciones políticas es prioritario para la democracia. Se deberá prestar atención especial a la problemática derivada de los altos costos de las campañas electorales y al establecimiento de un régimen equilibrado y transparente de financiación de sus actividades.

\section{Artículo 6}

La participación de la ciudadania en las decisiones relativas a su propio desarrollo es un derecho y una responsabilidad. Es también una 
condición necesaria para el pleno y efectivo ejercicio de la democracia. Promover y fomentar diversas formas de participación fortalece la democracia.

\author{
II \\ LA DEMOCRACIA Y LOS DERECHOS HUMANOS
}

\title{
Artículo 7
}

La democracia es indispensable para el ejercicio efectivo de las libertades fundamentales y los derechos humanos, en su carácter universal, indivisible e interdependiente, consagrados en las respectivas constituciones de los Estados y en los instrumentos interamericanos e internacionales de derechos humanos.

\section{Artículo 8}

Cualquier persona o grupo de personas que consideren que sus derechos humanos han sido violados pueden interponer denuncias o peticiones ante el sistema interamericano de promoción y protección de los derechos humanos conforme a los procedimientos establecidos en el mismo.

Los Estados Miembros reafirman su intención de fortalecer el sistema interamericano de protección de los derechos humanos para la consolidación de la democracia en el Hemisferio.

\section{Artículo 9}

La eliminación de toda forma de discriminación, especialmente la discriminación de género, étnica y racial, y de las diversas formas de intolerancia, así como la promoción y protección de los derechos humanos de los pueblos indígenas y los migrantes y el respeto a la diversidad étnica, cultural y religiosa en las Américas, contribuyen al fortalecimiento de la democracia y la participación ciudadana.

Artículo 10

La promoción y el fortalecimiento de la democracia requieren el ejercicio pleno y eficaz de los derechos de los trabajadores y la aplica- 
ción de normas laborales básicas, tal como están consagradas en la Declaración de la Organización Internacional del Trabajo (OIT) relativa a los Principios y Derechos Fundamentales en el Trabajo y su Seguimiento, adoptada en 1998, así como en otras convenciones básicas afines de la OIT. La democracia se fortalece con el mejoramiento de las condiciones laborales y la calidad de vida de los trabajadores del Hemisferio.

III

DEMOCRACIA, DESARROLLO INTEGRAL Y COMBATE A LA POBREZA

Artículo 11

La democracia y el desarrollo económico y social son interdependientes y se refuerzan mutuamente.

\section{Artículo 12}

La pobreza, el analfabetismo y los bajos niveles de desarrollo humano son factores que inciden negativamente en la consolidación de la democracia. Los Estados Miembros de la OEA se comprometen a adoptar y ejecutar todas las acciones necesarias para la creación de empleo productivo, la reducción de la pobreza y la erradicación de la pobreza extrema, teniendo en cuenta las diferentes realidades y condiciones económicas de los países del Hemisferio. Este compromiso común frente a los problemas del desarrollo y la pobreza también destaca la importancia de mantener los equilibrios macroeconómicos y el imperativo de fortalecer la cohesión social y la democracia.

\section{Artículo 13}

La promoción y observancia de los derechos económicos, sociales y culturales son consustanciales al desarrollo integral, al crecimiento económico con equidad y a la consolidación de la democracia en los Estados del Hemisferio.

\section{Artículo 14}

Los Estados Miembros acuerdan examinar periódicamente las acciones adoptadas $y$ ejecutadas por la Organización encaminadas a 
fomentar el diálogo, la cooperación para el desarrollo integral y el combate a la pobreza en el Hemisferio, y tomar las medidas oportunas para promover estos objetivos.

\section{Artículo 15}

El ejercicio de la democracia facilita la preservación y el manejo adecuado del medio ambiente. Es esencial que los Estados del Hemisferio implementen politicas y estrategias de protección del medio ambiente, respetando los diversos tratados y convenciones, para lograr un desarrollo sostenible en beneficio de las futuras generaciones.

\section{Artículo 16}

La educación es clave para fortalecer las instituciones democráticas, promover el desarrollo del potencial humano y el alivio de la pobreza y fomentar un mayor entendimiento entre los pueblos. Para lograr estas metas, es esencial que una educación de calidad esté al alcance de todos, incluyendo a las niñas y las mujeres, los habitantes de las zonas rurales y las personas que pertenecen a las minorías.

IV

FORTALECIMIENTO Y PRESERVACIÓN DE LA INSTITUCIONALIDAD DEMOCRÁTICA

\section{Artículo 17}

Cuando el gobierno de un Estado Miembro considere que está en riesgo su proceso político institucional democrático o su legítimo ejercicio del poder, podrá recurrir al Secretario General o al Consejo Permanente a fin de solicitar asistencia para el fortalecimiento y preservación de la institucionalidad democrática.

\section{Artículo 18}

Cuando en un Estado Miembro se produzcan situaciones que pudieran afectar el desarrollo del proceso político institucional democrático o el legítimo ejercicio del poder, el Secretario General o el Con- 
sejo Permanente podrá, con el consentimiento previo del gobierno afectado, disponer visitas y otras gestiones con la finalidad de hacer un análisis de la situación. El Secretario General elevará un informe al Consejo Permanente, y éste realizará una apreciación colectiva de la situación y, en caso necesario, podrá adoptar decisiones dirigidas a la preservación de la institucionalidad democrática y su fortalecimiento.

\section{Artículo 19}

Basado en los principios de la Carta de la OEA y con sujeción a sus normas, y en concordancia con la cláusula democrática contenida en la Declaración de la ciudad de Quebec, la ruptura del orden democrático o una alteración del orden constitucional que afecte gravemente el orden democrático en un Estado Miembro constituye, mientras persista, un obstáculo insuperable para la participación de su gobierno en las sesiones de la Asamblea General, de la Reunión de Consulta, de los Consejos de la Organización y de las conferencias especializadas, de las comisiones, grupos de trabajo y demás órganos de la Organización.

\section{Artículo 20}

En caso de que en un Estado Miembro se produzca una alteración del orden constitucional que afecte gravemente su orden democrático, cualquier Estado Miembro o el Secretario General podrá solicitar la convocatoria inmediata del Consejo Permanente para realizar una apreciación colectiva de la situación y adoptar las decisiones que estime conveniente.

El Consejo Permanente, según la situación, podrá disponer la realización de las gestiones diplomáticas necesarias, incluidos los buenos oficios, para promover la normalización de la institucionalidad democrática.

Si las gestiones diplomáticas resultaren infructuosas o si la urgencia del caso lo aconsejare, el Consejo Permanente convocará de inmediato un período extraordinario de sesiones de la Asamblea General para que ésta adopte las decisiones que estime apropiadas, incluyendo gestiones diplomáticas, conforme a la Carta de la Organización, el derecho internacional y las disposiciones de la presente Carta Democrática. 
Durante el proceso se realizarán las gestiones diplomáticas necesarias, incluidos los buenos oficios, para promover la normalización de la institucionalidad democrática.

\section{Artículo 21}

Cuando la Asamblea General, convocada a un período extraordinario de sesiones, constate que se ha producido la ruptura del orden democrático en un Estado Miembro y que las gestiones diplomáticas han sido infructuosas, conforme a la Carta de la OEA tomará la decisión de suspender a dicho Estado Miembro del ejercicio de su derecho de participación en la OEA con el voto afirmativo de los dos tercios de los Estados Miembros. La suspensión entrará en vigor de inmediato.

El Estado Miembro que hubiera sido objeto de suspensión deberá continuar observando el cumplimiento de sus obligaciones como miembro de la Organización, en particular en materia de derechos humanos.

Adoptada la decisión de suspender a un gobierno, la Organización mantendrá sus gestiones diplomáticas para el restablecimiento de la democracia en el Estado Miembro afectado.

\section{Artículo 22}

Una vez superada la situación que motivó la suspensión, cualquier Estado Miembro o el Secretario General podrá proponer a la Asamblea General el levantamiento de la suspensión. Esta decisión se adoptará por el voto de los dos tercios de los Estados Miembros, de acuerdo con la Carta de la OEA.

\section{$\mathrm{V}$}

LA DEMOCRACIA Y LAS MISIONES DE OBSERVACIÓN ELECTORAL

\section{Artículo 23}

Los Estados Miembros son los responsables de organizar, llevar a cabo y garantizar procesos electorales libres y justos.

Los Estados Miembros, en ejercicio de su soberanía, podrán solicitar a la OEA asesoramiento o asistencia para el fortalecimiento $y$ 
desarrollo de sus instituciones y procesos electorales, incluido el envio de misiones preliminares para ese propósito.

\section{Artículo 24}

Las misiones de observación electoral se llevarán a cabo por solicitud del Estado Miembro interesado. Con tal finalidad, el gobierno de dicho Estado y el Secretario General celebrarán un convenio que determine el alcance y la cobertura de la misión de observación electoral de que se trate. El Estado Miembro deberá garantizar las condiciones de seguridad, libre acceso a la información y amplia cooperación con la misión de observación electoral.

Las misiones de observación electoral se realizarán de conformidad con los principios y normas de la OEA. La Organización deberá asegurar la eficacia e independencia de estas misiones, para lo cual se las dotará de los recursos necesarios. Las mismas se realizarán de forma objetiva, imparcial y transparente, y con la capacidad técnica apropiada.

Las misiones de observación electoral presentarán oportunamente al Consejo Permanente, a través de la Secretaría General, los informes sobre sus actividades.

\section{Artículo 25}

Las misiones de observación electoral deberán informar al Consejo Permanente, a través de la Secretaría General, si no existiesen las condiciones necesarias para la realización de elecciones libres y justas.

La OEA podrá enviar, con el acuerdo del Estado interesado, misiones especiales a fin de contribuir a crear o mejorar dichas condiciones.

VI

Promoción de la cultura democrática

Artículo 26

La OEA continuará desarrollando programas y actividades dirigidos a promover los principios y prácticas democráticas y fortalecer 
la cultura democrática en el Hemisferio, considerando que la democracia es un sistema de vida fundado en la libertad y el mejoramiento económico, social y cultural de los pueblos. La OEA mantendrá consultas y cooperación continua con los Estados Miembros, tomando en cuenta los aportes de organizaciones de la sociedad civil que trabajen en esos ámbitos.

\section{Artículo 27}

Los programas $y$ actividades se dirigirán a promover la gobernabilidad, la buena gestión, los valores democráticos y el fortalecimiento de la institucionalidad política y de las organizaciones de la sociedad civil. Se prestará atención especial al desarrollo de programas y actividades para la educación de la niñez y la juventud como forma de asegurar la permanencia de los valores democráticos, incluidas la libertad y la justicia social.

\section{Artículo 28}

Los Estados promoverán la plena e igualitaria participación de la mujer en las estructuras políticas de sus respectivos países como elemento fundamental para la promoción y ejercicio de la cultura democrática. 